IRA-International Journal of Education \& Multidisciplinary Studies

ISSN 2455-2526; Vol.07, Issue 03 (2017)

Pg. no. 184-189

Institute of Research Advances

http://research-advances.org/index.php/IJEMS

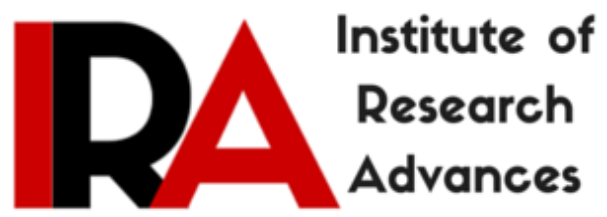

\title{
Role of Information and Communication Technology (ICT) in Teacher Education
}

\section{Ruwndar Lastny Anal}

Research Scholar, Department of Education, North Eastern Hill University, Shillong, India.

Type of Review: Peer Reviewed.

DOI: http://dx.doi.org/10.21013/jems.v7.n3.p2

\section{How to cite this paper:}

Lastny Anal, R. (2017). Role of Information and Communication Technology (ICT) in Teacher Education. IRA International Journal of Education and Multidisciplinary Studies (ISSN 24552526), 7(3), 184-189. doi:http://dx.doi.org/10.21013/jems.v7.n3.p2

(C) Institute of Research Advances.

\section{(cc) EY-NO}

This work is licensed under a Creative Commons Attribution-Non Commercial 4.0 International License subject to proper citation to the publication source of the work.

Disclaimer: The scholarly papers as reviewed and published by the Institute of Research Advances (IRA) are the views and opinions of their respective authors and are not the views or opinions of the IRA. The IRA disclaims of any harm or loss caused due to the published content to any party. 


\section{ABSTRACT}

We are in the era of information where technology plays an important role to transact the information to the needed individuals in the education system. With the implementation of two years B.Ed. Programme, based on the recommendations of the Justice Verma Commission (2012), there has been a paradigm shift from the teacher centred to student-centred in the training of student teachers. There needs a proper propagation of knowledge in education which is possible through communication. ICT is a part of non-verbal form of language which is very effective in communication with respect to educational context. To make the teaching learning effective the responsible teachers should adapt or have positive attitude towards the use of ICT in education system. This makes the teachers comfortable in his/her teaching and can best expect the effective outcomes among the learners. This theoretical paper discusses about the role of ICT in Teacher Education and better transaction of teaching learning process through the use of ICT.
\end{abstract}

Keywords: ICT, Teacher Education.

\title{
Introduction
}

To understand the term 'education' in its right perspective is perceived by very few though this common word is used by vast number of people. Education is considered to be a lifelong process of learning irrespective of the age, time and situational field. The learning continues as long as one has the right attitude towards learning. According to dictionary of education, (C.V. Good, 1973) education is defined as "the aggregate of all the processes by which a person develops abilities, attitudes and other forms of behaviour of practical values in the society in which s/he lives. The society synchronises with the rapid changing world which has an immediate impact on the system of education. The world now communicates with oneself in terms of delivering information with the trend of technologies. Being a responsible person either as a student or future teacher, it is essential to shape the meaning of education according to what time demands which will help to develop the purpose of becoming a teacher and thus helping the students. Therefore, education helps and radically transforms the human kind to adapt with the technological fast changing environment that is taking place. The teacher has a great role to render his or her service to the society, s/he must be ready to develop the skills of imparting the required knowledge and information to the learners as per to the changing society to what we called the Information and Communication Technological world.

\section{Information and Communication Technology (ICT)}

Information and Communication Technology (ICT) integration in education is the most striking innovation in educational field. There is a need that every educational institution should cope with the suddenly increasing demand for information and skills. The various ranges of ICT tools which can be tried in education should be made accessible in every educational institution.

It can be regarded that ICT is the catchall phase used to describe a range of technologies for gathering, storing, retrieving, processing, analysing and transmitting information. Advances in ICT have progressively reduced the cost of managing information, enabling individuals and organisation to undertake information-related tasks much more efficiently, and to introduce innovation in products, processes and organisational structures. The objective of using ICT in education must be to create an environment where every learner can access rich educational resources, teachers and experts and even their peers for collaborative learning.

UNESCO devotes significant attention to the use of new ICTs and with good reason associates ICTs with expanding new cultural, social, cognitive and professional horizons of education at national, regional and global levels. The use of ICTs could be the most important factor ensuring stable global development. While recognizing the achievements of and prospects for using ICTs in education, the world community cannot ignore various pitfalls they entail. 
ICT keeps on growing in its own respective huge dimensions. Anyhow, each and every innovated technology should be made aware so that the educational institutions can grab the opportunity to access with the latest information and skills.

\section{ICT and Teacher Education}

In education, interactivity holds an utmost importance, i.e. two ways process of communication is important for teaching and learning. It is the technology basically the ICT which has help to achieve this. There has been transformation in learning environments with the generation of new information sources and new learning processes which have reflected to changing the role of teachers. With the advent of ICT and the development of knowledge-based societies, their roles need to be redefined. Teachers are no longer dispensers of knowledge but are proactive facilitators who promote collaborative knowledge building and guide students, to navigate and process a multitude of information resources, and to use these resources in solving problems and making decisions on their own. ICT plays as an important aid in teaching and learning process in this view.

Thus, the institutions of teacher education take the important part in changing the role of the teachers which is the demand of the present time that the student teachers are trained with the required skills of using ICT in the classroom atmosphere. In the light of this, the place of ICT takes a toll in the present constructivist design of teacher education programme involving critical thinking and the application of insight to process information. This is highlighted in the two years B.Ed. programme recommended by Justice Verma Commission, 2012. Accordingly, the NCTE prepared the curriculum framework for teacher to prepare quality teachers with adequate time of training and requisite competencies of teaching integrating ICT into day-to-day classroom instruction.

In the rapidly changing socio-economic scenario, teaching and learning and also training through technology is becoming common. It is essential to remain abreast of the latest developments in one's respective field; one has to undergo training regularly. Teacher should be prepared to take full advantage of the potentials of ICT, but not for the sake of technology itself. This is a tough challenge for the teacher training institutes, but one they cannot escape from. This means that the role of ICT in teacher training should be considered in a larger perspective, including the other educational fields. There has been a paradigm shift from teacher-centred to student-centred in teaching and learning process. The teacher task is as a facilitator in the learning programme wherein the role of ICT is very important to enable knowledge attainable.

It requires the stakeholders of every institution to provide opportunities and environment by making available the necessary infrastructure so that both the teacher educators and student teachers access the ICT tools during the training period. Henceforth, the student teachers acquired the skills and in the process can disseminate the knowledge content to the school students /learner with the most appropriate use of ICT tools. It is very important for a teacher/trainer to understand how ICT technologies can be useful in different areas. Only then we will be able to integrate and implement in teaching and learning process.

\section{Role of ICT in Teacher Education}

ICT has revolutionised the society in general and education in particular. It is democratising education. It is assumed that a shift from teacher oriented arrangements of the learning process towards more student oriented arrangements can be facilitated by ICT. However, until now these potentials of ICT have hardly been implemented. Most of the current ICT- applications are used to facilitate the teacher oriented arrangements of the learning process.

It is obvious that the use of ICT as a medium in the learning process in the educational field, for which teachers are trained, implies that ICT is an aspect of the teaching profession. This means that during their pre-service and in-service training teachers have to be prepared on using to enhance learning process. In addition the training of teachers can be enhanced by making use of ICT. This refers to the use of ICT as a medium in the teacher training institutes. It has often been found that new teachers tend to teach in the same way as they were taught both when they were a child and when they were students in pre-service training. 
Use of ICT in educational system is vouch for its integration, i.e., embedment within the educational institution so that technology becomes an integral part of the instructional process. ICT should be used to support learning/training rather than just an information provider. Integration of ICT in the classroom captures the attention of the learners. Integrating ICT in the learning process is not only a matter of the infusion of new materials but it influences all aspects of the learning process. Not taking the interrelatedness of the driving forces of the learning process into account can be seen as a major obstacle for improvement of the learning process in general and for benefiting from the potentials of ICT.

The interrelatedness of the driving forces of the learning process is illustrated by the results of a study on the effects of using internet in education. Teachers who had used internet as part of the learning process noted the following changes (Siddique, 2004):

- The role of the teacher changed to that of facilitator and mentor.

- Students became active participants; discussions became more detailed and deeper;

- Access to information resources expanded significantly;

- Learners became more independent.

- Access to teachers became equal and direct.

- Interactions among teachers were increased significantly.

- Education became learner centred; learning became self-based;

- Learning opportunities for all students became more equal; learner-learner group; interactions were significantly increased.

- Teaching and learning increased.

- The teacher-learner hierarchy broke-down; teachers became learners; and learners became teachers.

It is assumed that ICT is an adequate medium to support the shift from teacher oriented towards more student oriented ways of learning. Although it is uncertain to what extent this shift will take place and how much time this will require, the direction of future is clear: the learner will become more responsible for the arrangement of his or her own learning process.

The challenge is not getting technology and computers into schools but integrating Information and Computer Technology into the teaching and learning process in order to improve the learning outcomes. Potential advantages of using ICT for the teaching learning process are, for example, that ICT can help students learn at their own pace, provide them with unlimited sources of information, offer access to other learners and mentors which can be motivating for students of all ages. ICT will be an important tool to facilitate the change of focus from the teacher to the student. This change also allows for making use of the main advantages of ICT for learning process: supporting more flexible learning for every student. Besides, it is assumed that every students has a basic right to be introduced into the information society and to benefit from ICT's motivating possibilities for the acquisition of knowledge,(basic ) skills and attitudes (the issue of equality).

Researches have to collaborate with institutes of teacher education and schools for primary and secondary education to focus on key issues. An essential element in helping the institution of teacher education to meet their challenges will be to monitor the progress and provide regular updates on the developments that take place. At the start of the programme baseline information is needed. Research is needed and should be encourage on the factors that influence successful use of ICT in education. Educational change is influenced by a complex set of interrelated factors. Although several research studies focussed on this issue, the knowledge base is still too limited to provide policy makers and educators with clear guidelines to which activities and support to focus on in order to make an innovation a success.

ICT can be of help to transform education from teacher to student orientation, to become more constructive and goal-oriented and prepare students for the information, break down barriers in schools and enhance 'real life quality' in learning. 


\section{Impact of ICT on Teacher Education}

As per to the need in education, teacher education has engulf ICT leaving a turn-over in its system. The role of the teachers has to adapt to the demand of prevailing situation as that of the provider, a facilitator. Thus, making teacher education is to take a vigorous step in training of inservice and future teachers for the purpose. It is very countable of the contribution made by ICT among teachers, students and education per se. Some of the impact can be describe as:

1. ICT enables teachers access to a vast source of the latest information and be updated.

2. It helps in getting authentic and current information. It creates awareness of innovative trends in instructional methodologies, evaluation process, etc.

3. It is a free-will tool. It thus makes the education democratised.

4. It engages and captures the learners' attention and motivates them throughout the learning process.

5. It provides an interaction situation which is the requirement for effective learning.

6. It encourages critical thinking and problem solving abilities.

7. It is an effective tool for information acquiring - thus students are encouraged to look for information from multiple sources and they can be more informed than before.

In fact, potentials of ICT can tremendously shift the orientation of teaching-learning approach from teacher-centric towards learner-centric approach. Therefore, the teachers must accept their great responsibility in the way that the students can learn best at their own capacity.

\section{Barriers to ICT integration}

Though ICT has brought a ton of advancements in education system, there are certain issues which make the teachers to integrate in their teaching due to a variety of reasons. After all, integration of ICT in teaching learning process is not an easy task. The elimination of the barriers prevailing is important for successful integration process.

Goktas et al (2009) supported the practice of many barriers still existed though a variety of action plans have been developed to effectively integrate ICTs in teacher education programmes. To facilitate these plans, barriers need to be identified so that they may be overcome. Main barriers can be identified when incorporating ICTs in education. Ertmer (1999) has classified barriers into two categories: extrinsic (first order) and intrinsic (second order). Extrinsic barriers include lack of resources, inadequate training, insufficient technical support, and lack of time; intrinsic barriers include teachers'/instructors' beliefs, visions concerning technology integration, and views about teaching, learning and knowledge. Some of the major barriers to ICT integration are the following:

- Inadequate access to technology: Accessing not only to advanced technologies but also the relatively simple ones is difficult.

- Lack of support to administration: Procuring technology, setting up the infrastructure for it, training teachers, etc. have to be managed by the administrator.

- Government policies: Policies framed by the government along with financial support will enforce ICT integration.

- Availability of necessary infrastructure: Proper equipment with consistent power supply that enables accessing of ICT must be available.

- Curriculum: The curriculum should be flexible and learner centred to include activities that require the use of ICT for learning.

- Evaluation pattern: Process evaluation rather than product evaluation can be given more importance.

- Lack of positive attitude on the part of the teacher: The attitude towards the ICT usage must be change in appositive angle.

- Professional development for teachers: Teachers need to be trained to enable them to use technology.

- Overcrowded classrooms: High teacher-student ratio is not conducive for integration of technology within the classroom. 
With these issues, it can be taken that teacher education should be highlighted of the fact that teachers in the actual process of teaching and learning dealt with certain barriers which must be faced as a challenge and should try to overcome them.

\section{Conclusion}

The education system must synchronise with the advancement in technologies. ICT holds as a concrete tool for the teachers to execute the teaching learning experiences with respect to the learner centric approach. Integrating ICT in teaching and learning process serves an immense productivity in the effective outcome of the learners. There is no way that ICT in education can be isolated. In the present scenario, a lot of improvements need to be taken care of with regard to implementation and integration of ICT in educational field. On one hand, teacher educational institutions should encourage and provide professional development programme on a continuous basis to keep teachers updated with information and skills of ICT. And on the other hand, the teachers themselves have to nurtured a positive attitude towards the use of ICT and be enthusiast about it. It is also equally important to keep in mind that certain hurdles against the integration of ICT are eliminated. If the attainment on the integration of ICT in education is smoothly feasible, then the future of Indian citizen lies not behind the developed countries.

\section{References}

1. Arulsamy, S., \& Kumar, P. S. (2009). Application of ICT in Education. New Delhi: Neelkamal Publication Pvt. Ltd.

2. Ertmer, P. A. (1999). Addressing first- and second-order barriers to change: Strategies for technology integration. Educational Technology Research and Development, 47(4), 47-61.

3.

4. Goktas, Y., Yildirim, S., \& Yildirim, Z. (2009). Main barriers and possible enablers of ICTs integration into pre-service teacher education programs. Educational Technology \& Society, $12(1), 193-204$.

5. Ponni, V. (2016). Role of ICT in teacher education. Research Tracks, 179-181.

6. Siddique, M. H. (2004). Technology in Teacher Education. New Delhi: APH Publishing Corporation.

7. University, I. G. (2008). Communication and Information Technology. New Delhi: School of Education IGNOU. 